\title{
La investigación en Comunicación Educación abordada en las maestrías: Entre las fronteras tradicionales y las nuevas perspectivas
}

\author{
Research in Communication education addressed in masters: between traditional \\ borders and new perspectives.
}

\author{
Sandra Nieto Useche ${ }^{1}$ \\ Nieto U,Sandra \\ miradas $\mathrm{N}^{\circ} 14$ - 2016. ISSN: 0122 994X Págs 81 - 92 \\ Recepción: Junio 18 de 2016 \\ Aprobación: Octubre 03 de 2016 \\ Publicación: Diciembre 20 de 2016
}

\section{Resumen}

En convergencia con los objetivos que promueve el foro, abrir los horizontes de pensamiento tanto de la comunicación como de la educación, la ponencia con el título La investigación en Comunicación educación abordada en las maestrías: entre las fronteras tradicionales y las nuevas perspectivas presenta, brevemente, los resultados de investigación que se constituye como un aporte al debate actual en las Ciencias Sociales, centrados en dos componentes esenciales en el ámbito universitario: la investigación y la docencia. Además, reflexionar y debatir las problemáticas de las sociedades latinoamericanas, presentar propuestas políticas que incidan en los procesos de transformación de las realidades particulares de los países que conforman la región, y específicamente en la colombiana.

Desde una perspectiva crítica e interdisciplinar, se asume como proceso histórico, social y político la configuración de la investigación en la universidad colombiana, específicamente en las maestrías en comunicación educación. La investigación se desarrolla alrededor de cuatro puntos: 1. El reconocimiento de las corrientes originarias fundacionales gestadas en América Latina para reconocer su vigencia en el ámbito académico investigativo universitario; 2. Comunicación Educación un campo de encuentro, convergencia y resistencia; 3. Las ciencias sociales, la comunicación educación, en la Universidad; y, el 4. Cinco nodos temáticos y problémicos: un aporte a la perspectiva teórica en comunicación educación.

1 Procesos Sociales y Políticos en América Latina. Universidad Autónoma de Colombia. Facultad de Ciencias Humanas. sandranieto84@yahoo.com 
En la ponencia se presenta el primer aspecto sobre las corrientes fundacionales que se gestaron en la década de los años sesenta en América latina en comunicación popular y educación popular que convergen en lo que da como resultado un campo, con fronteras difusas, con reducciones, generalizaciones; propuestas que nacen de las propias comunidades, de las necesidades, con voz propia y con sus ideologías.

Palabras Clave: corrientes fundacionales, comunicación popular, educación popular, comunicación educación.

\section{Abstract:}

In line with the objectives of the forum, to open up the horizons of thought in both communication and education, this paper titled Research in Communication education addressed in masters: between traditional borders and new perspectives presents, briefly, the results of research that constitute a contribution to the current debate in Social Sciences, centered on two essential components in the university field: research and teaching. In addition to this, to reflect and debate the problems of Latin American societies, to present political proposals that influence the processes of transformation of particular realities of the countries that make up the region, and specifically Colombia.

From a critical and interdisciplinary perspective, the configuration of research in Colombian universities is assumed as a historical, social and political process, specifically in masters degrees in communication education. Research is developed around four points: 1. The recognition of original foundational currents in Latin America $\mathrm{i}$ order to recognize their validity in the academic field of university research; 2. Communication Education a field of encounter, convergence and resistance; 3 . Social sciences, communication education, in University; And, 4. Five thematic and problematic nodes: a contribution to the theoretical perspective in communication education.

The paper presents the first aspect, the foundational currents that were developed in the 1960s in Latin America around popular communication and popular education that converge in a field, with diffuse borders, with reductions and generalizations ; Proposals that are born of the communities themselves, of their needs, with their own voice and with their ideologies.

Key Words: foundational currents, popular communication, popular education, communication education.

En convergencia con los objetivos que promueve el foro, abrir los horizontes de pensamiento tanto de la comunicación como de la educación, la ponencia presenta, brevemente, los resultados de la investigación que se constituye como un aporte al debate actual en las Ciencias Sociales, centrados en dos componentes esenciales en el ámbito universitario: la investigación y la docencia. Además, reflexionar y debatir las problemáticas de las sociedades latinoamericanas, presentar propuestas políticas que incidan en los procesos de transformación de las realidades particulares de los países que conforman la región, y específicamente en la colombiana.

La contribución y los aportes a la comprensión crítica de las sociedades latinoamericanas mediante una investigación permiten profundizar el conocimiento de la realidad social, política e 
histórica de la región. Desde una perspectiva crítica e interdisciplinar, se asume como proceso histórico, social y político la configuración de la investigación en la universidad colombiana, específicamente en las maestrías en comunicación educación. Las investigaciones realizadas en los últimos seis años se desarrollan alrededor de cuatro puntos: 1. El reconocimiento de las corrientes originarias fundacionales gestadas en América Latina para sustentar su vigencia en el ámbito académico investigativo universitario; 2 . Comunicación Educación un campo de encuentro, convergencia y resistencia; 3 . Las ciencias sociales, la comunicación educación, en la Universidad; y, el 4. Cinco nodos temáticos y problémicos: un aporte a la perspectiva teórica en comunicación educación.

En la ponencia solo se presentará el primero, sobre las corrientes fundacionales en comunicación popular y educación popular, que se gestaron en la década de los años sesenta en América latina, y que convergen en la formación de un campo, que inicialmente, era considerado con fronteras difusas, con reducciones y generalizaciones. Antes de presentar el aspecto seleccionado, debido a que converge con los objetivos formulados en este encuentro, en primer lugar aclaro que concibo Comunicación Educación como un campo de encuentro, convergencia y resistencia. Reconocer el panorama de la investigación universitaria en comunicación educación a partir de las tendencias teóricas que sustentan la producción en las maestrías, entre 2009 2012, condujo a visibilizar los cambios experimentados en la construcción del campo y a pensar en el campo mismo a través de su trayectoria histórica, desde sus orígenes; lo que implica recorrer un territorio a través de unas coordenadas topográficas de la comunicación-educación trazadas por las trayectorias teóricas y las prácticas, tanto del proyecto moderno de escolarización como de los proyectos emancipadores. Algunos espacios que cruzan estas coordenadas son los institucionales-educativos, los mediáticos-tecnológicos y los socio-comunitarios, entre otros identificados por Valderrama (2009), docente investigador colombiano.

Por tanto, Comunicación educación es un espacio de encuentro de teorías, epistemologías, prácticas, experiencias y trayectorias que problematizan la formación de sujetos críticos y la construcción de sentidos, conocimientos y saberes en una sociedad inmersa en la globalización, que experimenta transformaciones culturales propias del cambio de época. Por eso se considera como un espacio de convergencia propicio para generar un diálogo de saberes. La riqueza del campo consiste en ofrecer un abanico de posibilidades para romper con lo formalmente establecido, institucionalizado, estandarizado; enfrentar lo hegemónico mediante la creación de respuestas alternativas abanderadas por comunidades, grupos sociales, étnicos, hombres y mujeres que convierten sus necesidades en propuestas, que participan en la resolución de conflictos y que crean mecanismos de participación en 
la toma de decisiones. El campo de la comunicación educación encierra, en sí mismo, la resistencia como posibilidad de transformación de la realidad social. En sus orígenes, de los que forman parte las corrientes paradigmáticas fundacionales latinoamericanas, se evidencian múltiples manifestaciones de resistir ante el poder hegemónico que representa a las instituciones encargadas de socializar, uniformar a los diversos grupos poblacionales de nuestra región y estandarizar la educación de los sujetos que los conforman. (Nieto Useche, 2014).

Asumir desde la investigación la concepción de campo permite realizar adquisiciones generales en estudios concretos, descubrir sus características, identificar las diferencias y los conflictos, y superar la limitante de especialidad en un área del conocimiento para así reconocer que es una construcción colectiva, un trabajo conjunto. (Bourdieu, 2003). Concibo la resistencia como posibilidad de pensar, sentir, vivir en condiciones realmente humanas; resistencia como alternativa para producir sentidos a través de la palabra en sus diversas manifestaciones y soportes físicos desde los sonidos, las piedras de las cavernas, las tablillas, el papiro, el níveo papel, hasta la incandescentes pantallas que recrean y abren las ventanas a mundos cercanos y lejanos; resistencia como uno de los tantos caminos posibles para formar e interpelar a sujetos críticos, autónomos, quienes conocen su realidad local en tensión con la global, que experimentan los cambios de época y tejen redes en la sociedad actual (Nieto Useche, 2014).

El campo de la Comunicación educación, con sus apuestas históricas latinoamericanas, establece relación entre reflexiones teóricas y prácticas de las pedagogías y de la comunicación alternativas y populares; además, esta perspectiva del campo se ha configurado a través de un proceso histórico social en el que ha perfilado un objeto de estudio intrincado y multifacético. Su complejidad radica en las distintas articulaciones que lo distinguen, es decir, el carácter vinculante entre comunicación, educación y transformaciones culturales. (Huergo, 2005). Por tanto, se reconoce que el campo es el resultado de un proceso histórico, de unas condiciones sociales que le confieren autonomía, lo distinguen en una dinámica y unas relaciones que se establecen en el seno de este sistema y lo integran como tal.

El reconocimiento de las corrientes originarias fundacionales gestadas en América Latina para evidenciar su vigencia y resignificación en el ámbito académico investigativo universitario

Las corrientes fundacionales en comunicación popular y educación popular, gestadas en la década de los años sesenta en América latina, convergen en lo que da como resultado el campo de la comunicación educación; propuestas que nacen de las propias comunidades, de sus necesidades; comunidades con voz propia, con sus ideologías; unos pueblos que en condiciones precarias se oponen a ser excluidos, homogeneizados, desconocidos desde sus raíces; que luchan contra esa aniquilación secular de sus tradiciones, saberes originarios y crean otras formas de educar, otras formas de comunicar que reciben distintas denominaciones comunitaria, alternativa, popular, para el desarrollo, educativa; y las relaciones que se establecen que muestran perspectivas teóricas reconocidas, entre ellas: comunicación y educación, Gabriel Kaplún, Uruguay; Comunicación/ educación/cultura Jorge Huergo, Argentina; educomunicación: Oliveira Soarez, Brasil; educación popular y comunicativa, Rosa María Alfaro, Perú; comunicacióneducación Eduardo Valderrama, Humberto Cubides, Colombia. 
El punto de partida de una investigación es la identificación de una necesidad, en este caso, la de saber cómo se ha consolidado teóricamente comunicación educación, desde la mirada de las maestrías, superando aquellos intentos iniciales que lo definían como difuso; o bajo la reducción instrumental; o la generalización: todo lo comunicativo es educativo y viceversa. El punto de llegada, son los aportes en la construcción de conocimiento sobre la relación entre comunicación y educación a partir de la revisión de las fuentes bibliográficas; además, la constatación de la vigencia de las corrientes paradigmáticas latinoamericanas educativas, comunicativas populares y alternativas; como las propuestas de dos autores como Paulo Freire, con la pedagogía de la liberación, cuyo énfasis es la palabra; y, de Mario Kaplún, quien distingue la existencia de una interrelación entre comunicación - educación, un punto en donde se entrecruzan los dos campos.

Aquellos que estudian e investigan la relación entre cultura y educación resignifican la perspectiva de la pedagogía del brasileño Paulo Freire, que da apertura a su obra con La educación como práctica de la libertad en 1967; después, en 1970, escribe Pedagogía del oprimido. Estas dos obras forman parte de las referencias conceptuales de las investigaciones, reflexiones, y de propuestas alternativas que permiten reconocer hoy su vigencia. Se sugiere una lectura de las fuentes primarias de acuerdo con las características, y problemáticas de la sociedad actual no como mera referencia o citados por otros autores.

También los aportes de Mario Kaplún son fuentes originarias que se registraron en sus libros: El comunicador popular y A la educación por la Comunicación, Una pedagogía de la comunicación; $L a$ Comunicación de Masas en América
Latina; La Educación para los medios, en la formación del Comunicador Social; La Educación por la Comunicación; y, La práctica de la educación comunicativa. En consecuencia, se le confiere un lugar predominante entre los enfoques paradigmáticos del campo.

En Colombia los antecedentes que han contribuido a la configuración del campo de la Comunicación-educación se ubican hacia los años 60, aunque, en ese momento no es clara la relación, se identifica un enfoque funcionalista recibido de Norteamérica, que promueve a la comunicación masiva como difusora de contenidos que por sí mismos cambiaban comportamientos colectivos; la comunicación se establecía de forma instrumental entre el emisor, el receptor y el mensaje. Más tarde en los años 70 se formula el modelo que centraba su interés en la reproducción ideológica, aquí las audiencias son percibidas como pasivas;

Este paradigma es el que se denomina Crítico, con bases marxistas y estructuralistas, porque los lenguajes masivos son los difusores de la ideología dominante con estrategias imperialistas internacionales; pero, aquí se reduce el estudio del proceso de comunicación a la reproducción social, es decir, que lo tecnológico se limita a los aparatos y los instrumentos, no se reconocen los lenguajes. En estas dos décadas predomina el enfoque instrumental. (Herrera, Pinilla, Díaz, Infante, 2005).

En las décadas de los años setenta yochenta, en América Latina se trazan otras tendencias en las experiencias en comunicación con y para los medios; así la investigación centra su interés en la dependencia cultural, los análisis de los sistemas ideológicos y las condiciones de recepción. También incide que la UNESCO comienza a promover proyectos de Educación para la Recepción 
Crítica de Medios de Comunicación, que orientaban las iglesias católicas y cristinas bajo la perspectiva de la Educación para la comunicación, a partir de la prescripción del Concilio Vaticano II, que origina la Pastoral de la Comunicación. (Olivari Reyes, 2002).

Otra vertiente teórica que aborda la relación entre la educación y los medios de comunicación es la Pedagogía de la comunicación, con enfoques tales como: el funcional-culturalista, que estudia de manera sistemática la comunicación como hecho cultural (British Film Institute, Association for Media Literacy, entre otros); los enfoques latinoamericanos, que asumen que los medios son de comunicación, (no de información ) se sustentan en conceptos como criticidad y el diálogo de Paulo Freire y Antonio Pasquali. Esta temática la trabaja Francisco Gutiérrez (1975) en el Lenguaje Total Pedagogía de los medios de comunicación. Y, Prieto Castillo (1992) en su publicación titulada Comunicación y educación.

En la década de los años ochenta, se despliegan las propuestas críticas alternativas que exaltan las luchas de las culturas populares que pretenden alcanzar la generación de políticas democráticas en comunicación. Las reflexiones giran en torno a tres temas: de los medios a las mediaciones (Jesús Martín-Barbero); medios, audiencias y mediaciones (Guillermo Orozco) y los procesos de hibridación cultural (Néstor García Canclini). En 1987 se publica la obra, que marca un cambio en los estudios e investigaciones de los procesos de comunicación, De los Medios a las mediaciones de Martín-Barbero, puesto que ubica el proceso comunicativo en el ámbito cultural, de las ciencias sociales, e invita a pensarlo desde las mediaciones, los usos, los modos y las diversas formas de producir sentidos. Presenta el proceso histórico de las categorías de análisis pueblo y masa, la relación entre pueblo y cultura. También, establece la relación entre masificación, industrialización, y la urbanización; y de cómo pensar desde la cultura, como espacio estratégico, las contradicciones sociales, el sentido de los nuevos movimientos políticos y de los sujetos-actores sociales; y, desde ahí la categoría emergente es la industria cultural.

En consecuencia se evidencia, con estos aportes, el giro que toman los estudios de los procesos comunicativos hacia nuevas formas de reconocer a los destinatarios de los mensajes como sujetos capaces de resistir a la imposición e influencia de los medios de comunicación. Sólo hasta la década de los años ochenta empiezan a visibilizarse otras lecturas de la realidad, las audiencias ahora se consideran activas, que es el inicio de lo que después se reconocería como cambio de paradigma con énfasis en la dimensión cultural. Entonces, ya en este punto se aclara que los autores se refieren al campo estableciendo la relación de varias formas que identifican perspectivas teóricas: Comunicación y Educación (intersección); Comunicación/ Educación (articulación), Comunicacióneducación (estratégica) y educomunicación (libertad de la palabra).

Otras perspectivas, en Colombia, entre ellas la de Fernando Aranguren Díaz hacia mediados de la década de los años noventa, y quien actualmente es el Director de la Maestría en Comunicación Educación de la Universidad Distrital, definen la comunicación como una dimensión esencial de la educación, de la praxis humana, de la vida social, y de la actividad cultural. A través de la educación se despliega la competencia comunicativa en el ser humano; sustenta ese presupuesto reconociendo una relación complementaria entre comunicación y educación, que permite redimensionar a la educación, descubrir su dimensión comunicativa. 
En ese momento la Revista Nómada $\mathrm{N}^{\circ} 5$, Universidad Central-IESCO, publicación especializada en este campo, en un ejemplar monográfico compila el tema Comunicación-educación una relación estratégica, pensada como tópico o problema de investigación y generación de propuestas de acción. Aquí se presentan artículos que marcaron trayectorias como Heredando el futuro. Pensar la educación desde la comunicación de Jesús MartínBarbero; Educación, medios de difusión y generación de conocimiento: hacia una pedagogía crítica de la representación, Guillermo Orozco; Fin o metamorfosis de la escuela, José Joaquín Bruner; Educación y comunicación: pedagogía y cambio cultural, Carlos Augusto Hernández; El sujeto de la educación, Germán Muñoz; Educación popular hoy: entre su refundamentación o su disolución, Marco Raúl Mejía; Comunicación- educación: algunas propuestas investigativas, Humberto Cubides, Carlos Eduardo Valderrama.

Desde la perspectiva de Ismar De Oliveira Soares, en ese mismo año, 2000, se sostenía que la educomunicación era un nuevo campo formado, que había adquirido autonomía, que se estaba consolidando. Una década después asevera que las prácticas educomunicativas, inicialmente alternativas, empiezan a movilizar grandes estructuras que buscan convertirse en programas de políticas públicas. Agrega que la configuración de la relación comunicación-educación como campo no puede concebirse como espacio cerrado y predefinido porque debe asumir de forma radical la búsqueda de una libertad especial, la libertad de la palabra. Los educomunicadores distinguen como una utopía el valor estratégico de la lucha por la libertad de la palabra; esta lucha se concreta en acciones en los espacios educativos.

A inicios de la década del 2000 Humberto Cubides y Miguel Alfonso, investigadores colombianos, a propósito de la propuesta del programa académico de la Especialización en Comunicación Educación de la Universidad Central, conciben el campo en comunicación-educación como relación estratégica para formular problemas de investigación. Consideraban que era un campo emergente, y que precisamente ese carácter estratégico le permitiría avanzar en su definición. También, dos investigadoras colombianas Amanda Castiblanco y Olga Lucía Bedoya, de un programa que abrió caminos como especialización, se consolidó como Maestría en Comunicación Educativa en la Universidad Tecnológica de Pereira, UTP, recuperan, y reflexionan sobre las investigaciones realizadas en las tesis (desde 1990 hasta 2002); y publican los resultados en el texto Modos de ver: los sentidos de la comunicación educativa (1990-2002).

Las diversas formas de situar la relación entre comunicación y educación conduce a pensar la comunicación en la educación propuesta por Daniel Prieto Castillo (2004) porque la comunicación transforma; se basa en dos expresiones "transformación educativa" y "construcción de conocimiento" que forman parte de la jerga de la escuela, pero son despersonalizadas; enfrenta la tendencia a asociar la transformación educativa con la implementación tecnológica; no obstante ese proceso se acompaña con la construcción del otro. Interpela y responde que los conceptos construir y transformar son procesos que se producen en el sujeto mismo, que implican construirse y transformase; así, pensar lo comunicacional llevaría a la innovación educativa porque se relacionaría con el propio ser, en su historia personal, el pasado (autoreconocimiento), el presente (interacción) y el futuro (proyección).

Uriel Espitia y Carlos Eduardo Valderrama (2009) consideran que el campo ha venido configurándose alrededor de nodos de 
tensión en los que confluyen tanto las trayectorias teóricas, como las trayectorias prácticas y profesionales. Son los siguientes: entre el proyecto de escolarización de la modernidad y los proyectos emancipadores de las pedagogías críticas; al quiebre de las instituciones tradicionales como la familia, los partidos políticos, la iglesia y la escuela; a las que relacionan con el conocimiento mismo y con el lugar de la información, la comunicación, y el conocimiento en la sociedad contemporánea, que implican descentramientos en la educación y la comunicación y el quinto nodo hace referencia a la tensión inherente a la construcción de subjetividades.

En la actualidad, entre los investigadores colombianos que debaten e investigan en el ámbito universitario son los siguientes: de la Universidad Central-IESCO, a partir de la convergencia entre principios, métodos y técnicas reflexivas se pretende comprender el sentido de las prácticas educativas y comunicativas de distintos colectivos sociales, es decir la Reflexividad y producción del conocimiento (2014), encontramos a Humberto Cubides; otros proyectos como Prácticas comunicativoeducativas de Bogotá y la región del altiplano: subjetividades, colectivos y acciones sociales (2012) ; además, Estado del arte sobre la investigación en medios de Comunicación en Colombia (2009), Investigador principal Carlos Eduardo Valderrama; Escuela y ciudad: tramas y vías para la formación ciudadana (2008), Investigadora principal, Sonia Rojas Campos; y, Comunicación, educación y ciudadanía. Discursos de actores escolares.

En la Universidad Distrital Francisco José de Caldas pretenden comprender los fenómenos que vinculan interacciones, consumos y creaciones relacionados con las "tecnología-infocomunicacionales", tal como lo propone Juan Carlos Amador (2013) porque éstos ocupan un lugar central en la vida de los sujetos, como los niños, niñas y jóvenes; en la forma de establecer relaciones entre humanos mediadas por las TIC (dispositivos y pantallas), y que modifican tanto los procesos de socialización como los mecanismos de construcción de saberes.

Otra publicación Infancias, cibercultura y subjetividades Modos de ser y estar en el mundo a través de las pantallas (2012), Amador Baquiro, (Compilador), expone la irrupción de la cibercultura y el cambio de época: acercamiento a sus núcleos constitutivos que le permite problematizar y producir saberes; a la vez, se constituyen en nodos de enunciaciones emergentes que han sido asumidas en diversas perspectivas académicas y experiencias de investigación. Advierte que, ante el amplio panorama, es una "delimitación necesaria" describir cuatro ámbitos problematizadores: la historicidad de lo contemporáneo: leer de otro modo sus metáforas; la cibercultura y la Comuniación/educación: virtualidad y producción de presencia; la constitución del sujeto contemporáneo: de la biopolítica a la noopolítica; y, la educación y la cibercultura: saberes otros e inteligencia colectiva.

En la Universidad Pedagógica Nacional, en la obra Educación y Comunicación del Capitalismo informacional al capitalismo cultural, Ancízar Narváez Montoya (2013) asume la relación entre comunicación educación como "esferas propias de la reproducción y la reproducción cultural", por eso se plantearía no como una relación entre instituciones (escuela y medios) sino como una relación entre culturas. Identifica dos efectos del modelo de desarrollo imperante, des-ilustración e infantilización que repercuten sobre la subjetividad individual y la productividad colectiva. Propone la articulación desde los estudios culturales, la economía política, la ética, la política y la estética como esferas de la vida social, parte y producto de la cultura, es decir, la cultura misma. 
En consecuencia, después de esta aproximación a las tendencias teóricas, se reconoce como rasgo distintivo el movimiento permanente del campo; se trata de un campo relacional, que reconoce las constantes transformaciones culturales a las que se encuentra enfrentada la sociedad actual. La invitación, desde sus orígenes, es recorrer un territorio a través de unas coordenadas topográficas de la comunicación-educación trazadas por las trayectorias teóricas y las prácticas.

En conclusión, situarse en los antecedentes de conformación del campo de la comunicación educativa y la comunicación educación en Colombia es reconocer los procesos, los aportes, las trayectorias de los campos de la comunicación y la educación a mediados de la década del 50, que se articulan con los procesos sociales, políticos, económicos, culturales de la región en los que se gestaban las propuestas alternativas, emancipadoras, populares reconocidas como las corrientes paradigmáticas comunicativas educativas de América Latina, que fueron emergiendo alimentadas por los aportes teórico prácticos de Freire y Kaplún.

El propósito de reconocer los cambios que se han producido en la construcción del campo de la comunicación educación, en su trayectoria histórica para configurar su concepción actual a través de las investigaciones realizadas desde 2010 a 2016, permite presentar las siguientes conclusiones:

- A mediados de los cincuenta principios de los sesenta, se vivieron procesos socioculturales en un escenario desarrollista, delineado por las tendencias económicas mundiales y de América Latina, que condicionaron el desarrollo cultural, educativo y comunicativo. En este momento, situado en la segunda postguerra, es cuando se difunde la ideología del desarrollismo, que buscaba la modernización social basada en un capitalismo modernizante, la industrialización y en la idea de elevar los niveles científicos y tecnológicos. Aquí, desempeñaban una función socializadora la escuela y los medios como agentes para educar a los sujetos.

Se reconoce en la etapa fundacional del campo -desde la perspectiva de los procesos socioculturales, políticos, económicos- la relación entre el modelo económico del desarrollismo y el modelo de comunicación que se gesta asociado con el ideal de difundir la educación a esa gran masa rural, analfabeta en Colombia y América Latina en torno al papel relevante de los medios de comunicación, especialmente la radio por su gran cobertura y acogida; es lo que se reconoce como el difusionismo. Desde esta concepción de la difusión de innovaciones y la modernización, los medios de comunicación se convierten en agentes de modernización y desarrollo, debido al poder que se les asignaba al diseminar a gran escala y en distintas dimensiones los ideales, las prácticas, los medios que caracterizaban a la modernidad, tal como lo manifiesta Huergo (2005).

- Entre las propuestas fundacionales colombianas en comunicación educativa se encuentran los proyectos radiofónicos de emisoras como Radio Kennedy y Radio Sutatenza, entre otras, que crearon proyectos educativos orientados a instruir a los oyentes acerca de emergencias y labores del hogar. Radio Sutatenza marca un hito en lo que se refiere a las posibilidades de la radio educativa en Colombia dada su capacidad de gestión de recursos, cobertura de sus programas radiales y su estrategia de aprendizaje. (Hurtado, Arévalo y Ríos, s/f). 
En Colombia, en la década de los años sesenta cuatro universidades trazaban sus caminos en la investigación en educación a través de las facultades de educación, que posteriormente se consolidarían como maestrías en educación: Universidad Nacional de Colombia, Universidad Pedagógica Nacional; maestrías en Comunicación educativa: Universidad Tecnológica de Pereira; y maestría en Comunicación Educación de la Universidad Distrital Francisco José de Caldas. Estas instituciones públicas de educación superior, a partir de sus trayectorias se han constituido como agentes que promueven la investigación, y que en la actualidad forman parte del Sistema Colombiano de Ciencia y Tecnología.

- En América Latina en las décadas de los años 70 y 80 se comienza a manifestar, en una serie de experiencias en educación con y para los medios, una etapa decisiva en el desarrollo de la comunicación. En los años 70, los modelos norteamericanos de análisis de la comunicación pierden fuerza en América Latina y la investigación se vuelca hacia la dependencia cultural, los análisis de los sistemas ideológicos y las condiciones de recepción. (De Oliveira Soares, 1992 citado por Olivari Reyes, 2002). En estas décadas la educación para los medios de comunicación comenzó a desarrollar programas, diseños metodológicos creados desde diversas perspectivas ideológicas, teóricas y conceptuales.

- Se concluye que hacia 1985 son aportes esenciales para la investigación en Comunicación Educación -porque se consideran como baluartes que permitieron consolidar el campo- la creación de los centros de Investigación IESCO de la Universidad Central, El Colegio Académico en Comunicación Educación, CAECE, de la Universidad Pedagógica Nacional y el CINEP, Centro de Investigación y Educación Popular. También, la creación de los Programas Nacionales de Ciencia y Tecnología, PNCyT; y, hacia1996 se generó el mecanismo de reconocimiento de los grupos y los centros de investigación a través de procesos de medición.

- En los años noventa se inicia "la internacionalización de la ciencia en Colombia cuando Colciencias impulsó la Red Caldas que vinculó a más de 1200 investigadores colombianos residentes en el exterior" (Colciencias, 2010 citado por Londoño). Es importante señalar que en ese momento surge como un mecanismo para organizar las actividades de investigación la promoción de los sistemas de investigación de las instituciones, con mayor énfasis en las universitarias, alrededor del concepto de grupos de investigación (Londoño, 2005). (Molina R; Sánchez-Torres JM, 2010, p.6).

- A finales del siglo XX, es claro que en la sociedad global con las tensiones propias que emergen de lo local, afloran las consecuencias de las transformaciones culturales a las que se encuentran expuestas las instituciones tradicionales como la familia, la escuela, la iglesia y el Estado; entre esos cambios se reconoce la apertura de otros espacios de formación de sujetos y la producción de sentidos. Así, emergen y se consolidan como nuevos escenarios de formación 
los medios de comunicación, en el contexto de la crisis que enfrenta la escuela y la educación - que abarca desde el currículo, el profesorado, el lenguaje, hasta la gestión de la institución educativa- en consecuencia de la irrupción de las TIC y de la sociedad en red. Desde este panorama, con énfasis en la dimensión cultural y política. Por tanto, se reflexiona sobre la relación entre Comunicación educación, en la que es posible asumir las proyecciones de los medios, de las TIC más allá de su inserción en la escuela y la vida cotidiana, es decir, reconocerlos como creadores de sentidos, como generadores de los patrones culturales políticos, porque son mediadores en la producción de los mensajes de los sujetos sociales y políticos.

- Para finalizar, se reconoce que en Colombia quienes crearon $\mathrm{y}$ gestaron los programas académicos de postgrados y han reflexionado, estudiado e investigado en el campo, son referentes ineludibles: Olga Lucía Bedoya, Maestría en Comunicación Educativa, la primera en ser creada en el año de 1986 por la Universidad Tecnológica de Pereira; Alma Montoya, María Cristina Asqueta, Especialización en Comunicación Educativa, de la UNIMINUTO; Carlos Eduardo Valderrama, Humberto Cubides, y Germán Muñoz en la Especialización en Comunicación-Educación de la Universidad Central, que ya no se ofrece como programa académico, continúa la Línea de investigación del IESCO; Boris Bustamante, Fernando Aranguren en la Especialización en Pedagogía de la Comunicación y Medios Interactivos que dio las bases para la creación de la Maestría en Comunicación- Educación de la Universidad Distrital Francisco José de Caldas; crearon y formaron parte de las líneas de investigación, el CACE, Colegio Académico en Comunicación Educación, Jesús Martín Barbero, Jorge Huergo, Alexis Pinilla; posteriormente se vinculó Ancízar Narváez, de la Universidad Pedagógica Nacional; y en la Línea en Comunicación Educación JM Pereira, Carlos Eduardo Gutiérrez, de la Pontificia Universidad Javeriana.

\section{Referencia Bibliográfica}

Aranguren Díaz, Fernando. (1996). La educación superior y las transformaciones de la comunicación. Bogotá: Nómadas (Col), Nº 5 , Universidad Central.

Amador Baquiro, Juan Carlos. (Compilador). (2012). Infancias, cibercultura y subjetividades Modos de ser y estar en el mundo a través de las pantallas. Bogotá: Universidad Distrital Francisco José de Caldas.

Cubides, Humberto y Valderrama, Carlos. (1996). Comunicación-educación: algunas propuestas investigativas. En Revista Nómadas, N5. Bogotá: Universidad Central.

Bedoya, Olga. (2002). Modos de ver: los sentidos de la comunicación educativa (1990-2002); una construcción desde la tesis de la maestría en comunicación educativa. Papiro.

De Oliveira Soares, Ismar. (2000). La comunicación/Educación como nuevo campo del conocimiento y el perfil de su profesional. En: Comunicaión- Educación, Coordenadas, abordajes y travesías. Bogotá: Universidad Central, DIUC - Siglo del Hombre.

Espitia, Uriel y Valderrama, Carlos. (2009). Hacia una apertura política del campo comunicación-educación.

Freire, P. (1997). La educación como práctica de la libertad. México: Siglo XXI. 
Freire, P. (2005). Pedagogía del Oprimido. México: Siglo XXI.

García Canclini, Néstor. (1993). Culturas Híbridas. Estrategias para entrar y salir de la modernidad. México: Grijalbo.

Gutiérrez, F. (1975). El lenguaje total. Pedagogía de los medios de comunicación. Buenos Aires: Humanitas.

Herrera, Martha Cecilia; Pinilla, Alexis V; Infante, Raúl; Díaz, Carlos. (2005). La construcción de cultura política en Colombia. Proyectos hegemónicos y resistencias culturales. Bogotá: Universidad Pedagógica Nacional.

Huergo, Jorge. (2005). Comunicación, cultura y educación: una genealogía. La Plata: Universidad Nacional de la Plata. [Consultado: 02/02/2014]. Disponible en: http://jorgehuergo. blogspot.com/

Hurtado, Hygcia Teresita; Arévalo, Sandra Patricia y Ríos Delgado, Mauricio. (s/f). Breve historia de la Radio Educativa en Colombia. Informe sobre radio educativa Ministerio de Educación Nacional, Programa Nacional de Uso de Medios y TIC. En Pagina web Colombia aprende.

Londoño F. (2005). Un análisis sobre la dinámica de los grupos de investigación en Colombia, de su conformación a su supervivencia. Investigación y Desarrollo.

Martín-Barbero, J. (1997). De los medios a las mediaciones. Comunicación, cultura y hegemonía. Barcelona: Gustavo Gili.

Molina Gallego, Rafael y Sánchez Torres, Marcela. (2010). Caracterización de los grupos de investigación una experiencia de aplicación de política pública en la Universidad Nacional de Colombia.

Narváez Montoya, Ancízar. (2013). Educación y Comunicación del Capitalismo informacional al capitalismo cultural. Bogotá: Universidad Pedagógica Nacional.
Nieto Useche, Sandra. (2014). Introducción y artículo. La noción de una nueva ciudadanía como proceso y estrategia. Entre la transición democrática, la reconfiguración del Estado y las propuestas alternativas. En: Comunicación Educación un campo de resistencias. Bogotá: UNIMINUTO.

Olivari Reyes, José Luis. (2002). Tradiciones teóricas fundacionales y relaciones entre comunicación y educación. Blog Nuevo Trato con el Estado. mazinger.sisib.uchile.cl/ repositorio/.../o20021041029teoriaseduc.com. do...'http://bloguchile.uchile.cl/

Prieto, Daniel. (1992). Comunicación y educación. Quito: CIESPAL.

Prieto, Daniel. (2004). la comunicación en la educación. Buenos Aires: Ciccus, La Crugía.

Universidad Central-IESCO. (1996). Revista Nómada $\mathrm{N}^{\circ}$ 5. Bogotá: Universidad CentralIESCO. 